\title{
Simvastatin vs. L-Carnitine: An Experimental Study on Optimizing Nerve Repair
}

\author{
Hamid NAMAZI ${ }^{1}$, Mohammad Jafar EMAMI ${ }^{1}$, Fatemeh DEHGHANI NAZHVANI ${ }^{1}$, Ali DEHGHANI NAZHVANI ${ }^{2}$ \\ ${ }^{1}$ Bone and Joint Diseases Research Center, Shiraz University of Medical Sciences, Shiraz, Iran \\ 'Department of Oral and Maxillofacial Pathology, School of Dentistry, Shiraz University of Medical Sciences, Shiraz, Iran \\ Corresponding author: Fatemeh DEHGHANI NAZHVANI fd_nazhvani@sums.ac.ir
}

\section{ABSTRACT}

AIM: To assay the effects of simvastatin and L-carnitine on peripheral nerve repair.

MATERIAL and METHODS: Left sciatic nerve of 70 female rats were cut and repaired under aseptic microsurgery. Based on medications and treatment period, seven groups were formed; control: no medication, SIM1W: one week daily oral simvastatin, LC1W: one week daily oral L-carnitine, Plb1W: one week daily oral placebo, SIM1M: one month daily oral simvastatin, LC1M: one month daily oral L-carnitine, Plb1M: one month daily oral placebo. Following 90 days, behavioral assessments and then histopathology were done.

RESULTS: Mean reflex time of withdrawal reflex latency and toe out angle in all experimented groups increased than normal. Long-term drug-medication significantly improved toe out angle. In long-term drug-medication, inflammation and neural bundle differentiation were significantly lower and higher, respectively. Vascular index showed reduction but number of myelinated nerve fibers had rises in drug-medicated groups compared to control and placebo groups. No obvious differences were detected in myeline diameter.

CONCLUSION: Both Simvastatin and L-carnitine can accelerate and improve the process of nerve regeneration in a long enough treatment period. The regulatory influence of these exogenous neurotrophic drugs may be essential to optimize regeneration of nerve fibers; so can broaden horizons for novel therapeutic modalities to decrease neuronal apoptosis.

KEYWORDS: Immune-modulation, L-Carnitine, Neurogenesis, Neuro-protection, Simvastatin, Rat

\section{INTRODUCTION}

W Tallerian degeneration after nerve injury causes axonal necrosis and release of inflammatory mediators by the necrotic axons, resident macrophages, and Schwann cells (SCs) $(23,29)$. Complicity and slow rate of axonal regeneration necessitate microsurgery for reconstruction of damaged nerves which is associated with nearly $50 \%$ satisfactory improvement in motor and sensory function in peripheral nervous system (PNS) (14). This is far less in central nervous system (CNS) conditions of neurosurgery (30). So adjuvant therapy can positively influence this process (19).

Improving the nerve metabolic capacity as well as response to neural growth factors (NGF) are the positive effects of simvastatin and L-carnitine as exogenous neurotrophic factors, which decrease neuronal loss after axotomy and improve neuronal regeneration (46). As an immunemodulatory drug, simvastatin may reduce retinal nerve fiber degeneration in acute optic neuritis (3). Indeed, simvastatin could ameliorate oxidative stress damage, abate inflammatory response, and restore nitroso-redox balance (41). On the other hand, L-carnitine is a neuron preserver which accelerates neuron regeneration independent of its impression on neuron survival (45). L-carnitine enhances regeneration of transected peripheral nerves without any biochemical alterations, which depends on neurotrophin and increase in aerobic glycolytic capacity (46). L-carnitine facilitates the transport of long-chain free fatty acids through the inner mitochondrial membrane,
Hamid NAMAZI $\quad$ (D) : 0000-0001-8823-2292

Mohammad Jafar EMAMI (D) : 0000-0001-6598-0968
Fatemeh DEHGHANI NAZHVANI (1) : 0000-0002-0498-7872

Ali DEHGHANI NAZHVANI (10): 0000-0002-9472-8793 
helps oxidative glycolysis, and shows anti-oxidative activity preventing the apoptosis in cells. It also enhances the expression and tendency of neurotrophin to NGF (45). So, L-carnitine contributes to enhanced generation of glutathione, which protects the nerves and cellular fibroblasts against elevated free radical activity. Indeed, it blocks the cell death pathway at the mitochondrial level by limiting bioenergetic dysregulation and synthesis of reactive oxygen species (45).

As most neuro-repair drugs are safe such as statins and L-carnitine (1), and given the lack of investigations on their clinical efficacy, this study was designed to assess their behavioral, macroscopical, and microscopical effects on nerve repair.

\section{MATERIAL and METHODS}

In this experimental study, 70 mature female white Wistar rats were used. The rats were housed $\left(22^{\circ} \mathrm{C}, 12\right.$ hours light and, 12 hours darkness) for which food and water were provided. The study was approved by the Research Ethics Committee of Shiraz University of Medical Sciences (Ref. No: 2017-347). Practical steps were done at animal laboratory of the Center of Comparative and Experimental Medicine of SUMS while following the ARRIVE guidelines (24). All the rats underwent surgical procedure, behavioral assessment, and histopathological evaluation.

\section{Surgery}

After anesthesia, the left hind limb was prepared for standard aseptic microsurgery. Via the gluteal muscle-splitting, the sciatic nerve was cut at the midway and repaired by microsutures in epineural sheath using prolene 8-0. Finally, the muscles and the skin were sutured. Post-op care continued for five days and the rats showed good recovery. The day after the surgery the medications started, with the rats randomly (using Random Number Table) categorized in seven groups of 10 rats, based on the oral medications and the treatment period. Group 1 (Control): The control group had no oral medication. Group 2 (SIM1W): Received oral simvastatin (8 $\mathrm{mg} / \mathrm{kg}$ ) daily for one week. Group 3 (LC1W): Received oral L-carnitine $(100 \mathrm{mg} / \mathrm{kg})$ daily for one week. Group 4 (Plb1W): Received oral placebo daily for one week. Group 5 (SIM1M): Received oral simvastatin $(8 \mathrm{mg} / \mathrm{kg})$ daily for one month. Group 6 (LC1M): Received oral L-carnitine $(100 \mathrm{mg} / \mathrm{kg})$ daily for one month. Group 7 (Plb1M): Received oral placebo daily for one month. The medication dosages were the same in all groups (1 mL).

\section{Behavioral Assessments}

According to the estimated time required for nerve sprouting to its other stump (33), and achieving functional recovery, the rats' follow up was terminated at the end of 90 days (13). The behavioral assessments were done on normal legs (in rats not undergoing surgery) as well as on the seven mentioned experimental groups.

\section{Withdrawal Reflex Latency (WRL)}

Following 90 days, the leg-WRL was measured based on the method published by Masters et al. (31). The rat was restrained and the hind paw was placed on a $56^{\circ} \mathrm{C}$ hot plate. The difference between operated and non-operated paws as increased time required to withdraw the paw was considered depressed nociceptive function. If there was no reflex after 12 seconds, the paw was removed from the hot plate to prevent tissue damage with the maximum WRL of 12 seconds assigned.

\section{Toe Out Angle (TOA)}

Evaluating the function of the hind limb, the TOA was assessed at the end of the $90^{\text {th }}$ post-op day based on Varejãoet al. method (42). The test was performed individually on a paper sheath $(100 \times 50 \mathrm{~cm})$, using red stamp to dye the foot pads and permit the rats to walk on it and have their foot prints. The TOA was measured as the angle between the walking direction and the reference line on the foot (the line from the calcaneus to the tip of the third digit).

\section{Histopathology}

After 90 days, the animals were euthanized and the entire sciatic nerve was dissected for microscopic evaluation. The samples were kept in $4 \%$ buffered formalin solution, embedded in paraffin, and sectioned. The sections were stained by hematoxylin and eosin (H\&E) for inflammation, neural bundle differentiation, and vascular index (VI, \%). They were also stained by Weil's method for a number of myelinated nerve fibers (MNF) per area unit and myelin sheath diameter (MD, $\mu \mathrm{m})$ (2). They were studied by Olympus microscope BX41 with the measurements performed by Image scope software version 2 in a single blind manner by the pathologist. Inflammation scored 0 as negative, $1+$ (mild), 2+ (moderate), 3+ (severe), and 4+ (necrosis); neural bundle differentiation was scored as 1 (no epineurium, mixture of neurons and fibroblasts), 2 (incomplete formation of epineurium), and 3 (complete formation of epineurium). Finally, the vascular index was equal to vascular area in a neural bundle divided by the neural bundle area.

\section{Statistical Analysis}

Kruskal Wallis test (followed by Mann-Whitney as post hoc test) and Analysis of Variance (followed by Duncan's multiple range as post hoc test) were performed for non-parametric and parametric data based on Levene statistic test. The analyses were conducted using SPSS package (SPSS 24 for Windows, SPSS Inc, Chicago, IL, USA). A p-value of $<0.05$ was considered as statistically significant.

\section{- RESULTS}

In clinical observation, the rats had some degree of lameness due to paralysis. Most of them did not lay down their feet. Some of them, especially in the control and placebo-received groups, had partially or fully mutilated their feet due to the absence of sensation and their auto-mutilation nature against injury.

\section{Behavioral Assessments}

\section{WRL}

All experimented groups had significantly a higher mean of WRL (more than $5 \mathrm{sec}$ ) compared to the normal legs [0.30, 


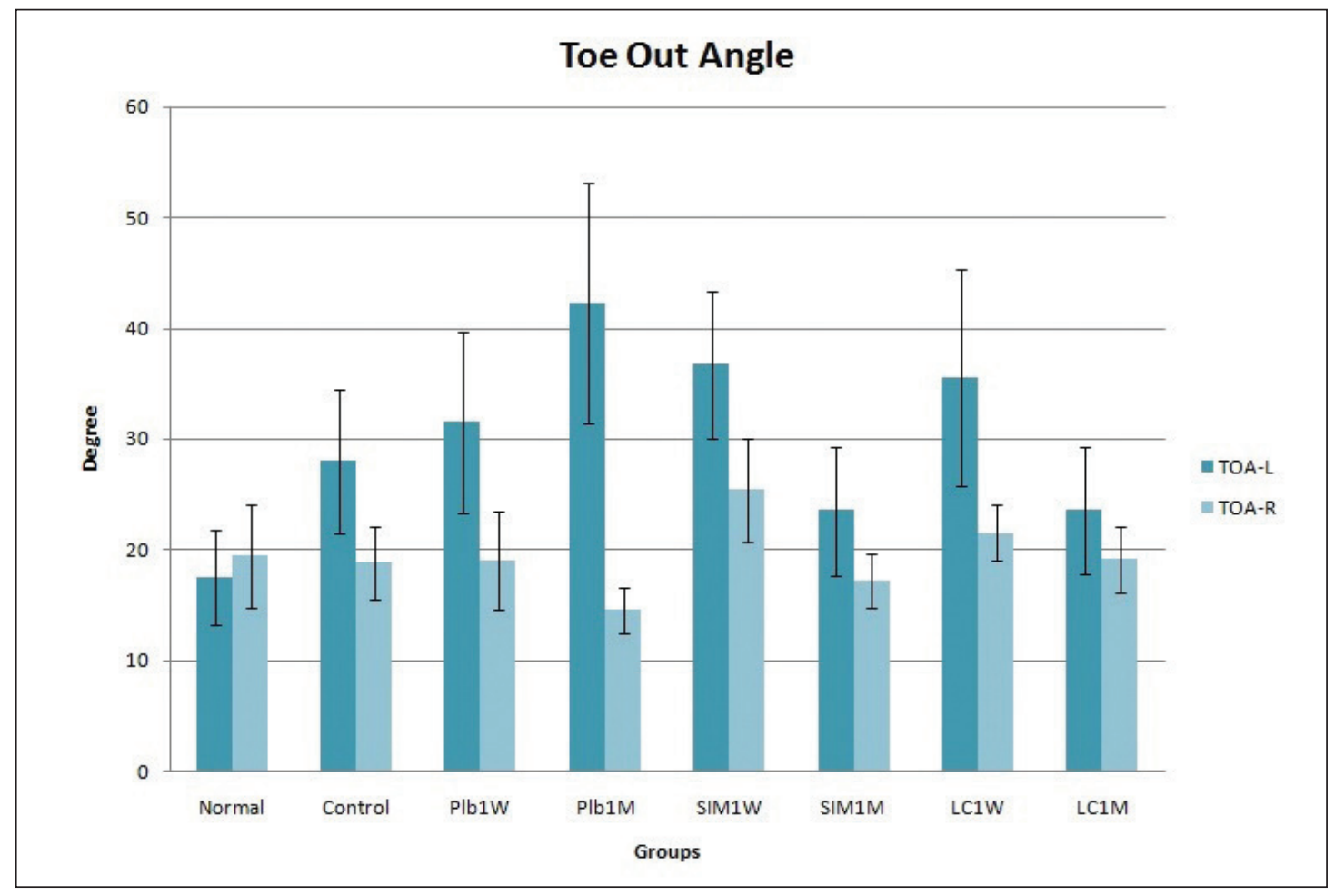

Figure 1: Bar chart showing the mean (SD) TOA-L and TOA-R degree of hind limbs of different groups;

(TOA-L= Operated/ Left TOA, TOA-R= NonOperated/Right TOA). TOA: Toe Out Angle.

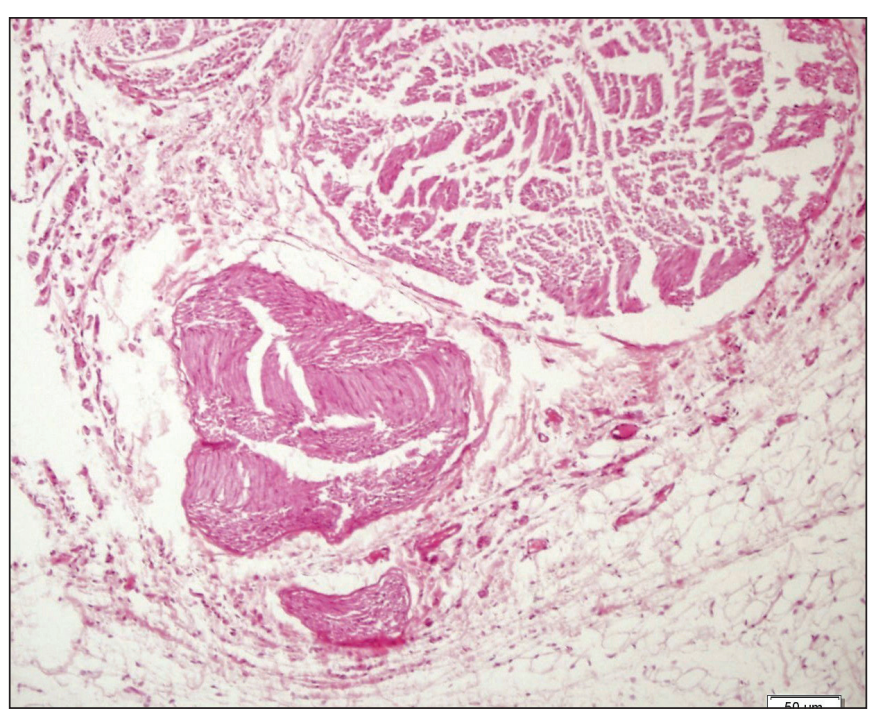

Figure 2: Longitudinal and cross sections of differentiated nerve bundles with complete epineurium without any inflammation (Hematoxylin \& Eosin stain, 100X).

Standard Deviation (SD) $0.22 \mathrm{sec}$ ( $(p<0.001)$, but no statistical difference was detected between the experimental groups $(p=0.189)$. Mean WRL of SIM1M (8.73, SD $3.70 \mathrm{sec})$ and LC1M (8.19, SD $3.39 \mathrm{sec})$ were closer to the control group $(9.53, \mathrm{SD}$ $3.42 \mathrm{sec})$ and higher than that of SIM1W $(5.44$, SD $4.73 \mathrm{sec})$ and LC1W (5.20, SD $4.13 \mathrm{sec})$.

\section{TOA}

The operated/left TOA (TOA-L) of all experimental groups were significantly higher than that of the normal $(p<0.001)$. The mean TOA-L of SIM1M (23.50, SD 5.77 degree) and LC1M (23.50, SD 5.71 degree) were closer to the normal (17.50, SD 4.14 degree). The differences were significant when comparing the groups of one-month and one-week drug-medicated, as well as between all drug-medicated groups and the control and placebo-received groups $(p<0.05)$.

TOA-L was higher in all experimental groups compared to the non-operated/right TOA (TOA-R). TOA-L and TOA-R were considerably close to each other in the normal legs; SIM1M and LC1M had more similar TOA-L and TOA-R among experimental groups (Figure 1). Paired t-test revealed a significant statistical difference in all groups except for the LC1M group and normal legs $(p=0.172$ and $p=0.743$, respectively).

\section{Histopathology}

Among experimental groups, the minimum inflammations were detected in one-month drug-medicated groups (SIM1M and LC1M). The differences were statistically significant between drug-medicated and placebo-received groups as well as between one-month and one-week drug-medicated groups $(p<0.05)$ (Figure 2).

All experimental groups showed heightened neural bundle differentiation compared to the control (Figure 3). Also, the drug-medicated groups revealed a higher differentiation degree than the placebo-received groups did especially SIM1M and LC1M. Nevertheless, these differences were not significant between the control and placebo-received groups, and between simvastatin and L-carnitine during the same course of medication therapy $(p<0.05)$. 
The VI showed reduction in drug-medicated groups especially SIM1M and LC1M. The highest mean of VI was observed in the control group (15.00, SD $2.82 \%$ ), which was statistically significant compared to the other groups $(p<0.05)$.

All drug-medicated groups demonstrated rises in MNF compared to the control and placebo-received groups, as LC1M had the highest mean number of MNF (22.33, SD 10.96), which was followed by SIM1M (18.66, SD 4.16). The differences were significant in SIM1M and LC1M compared to the control and placebo-received groups $(p<0.05)$.

No obvious differences were detected in MD among the experimented groups (Figure 4). Nevertheless, SIM1M indicated the minimum mean of $\mathrm{MD}(5.06, \mathrm{SD} 1.42 \mu \mathrm{m})$ followed by LC1M $(5.58$, SD $2.36 \mu \mathrm{m})$, which were not statistically significant $(p>0.05)$.

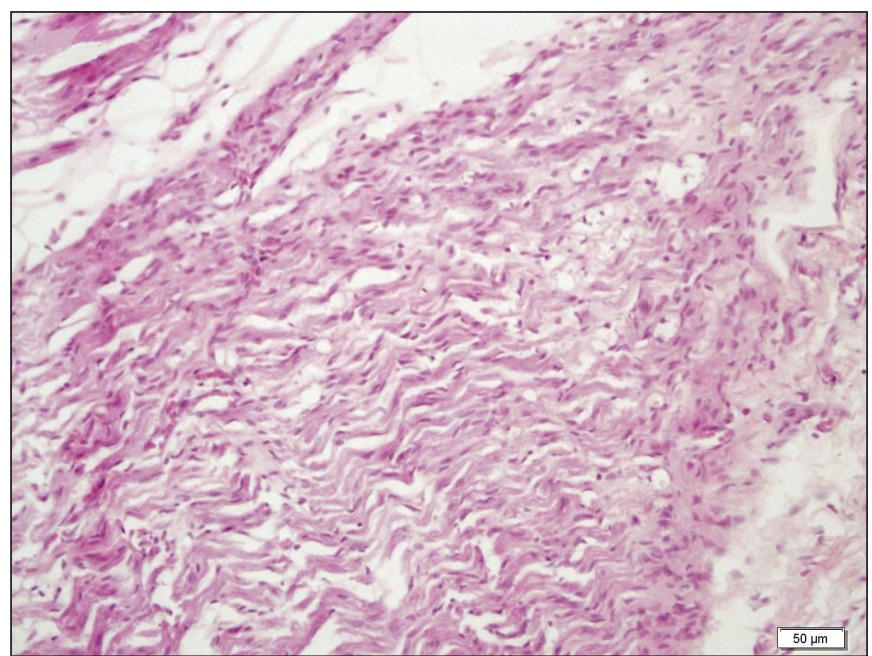

Figure 3: Mixture of neurons with wavy nuclei and fibroblasts with no obvious epineurium mimicking neurofibroma showing the initial stage of nerve repair (Hematoxylin \& Eosin stain, 200x).

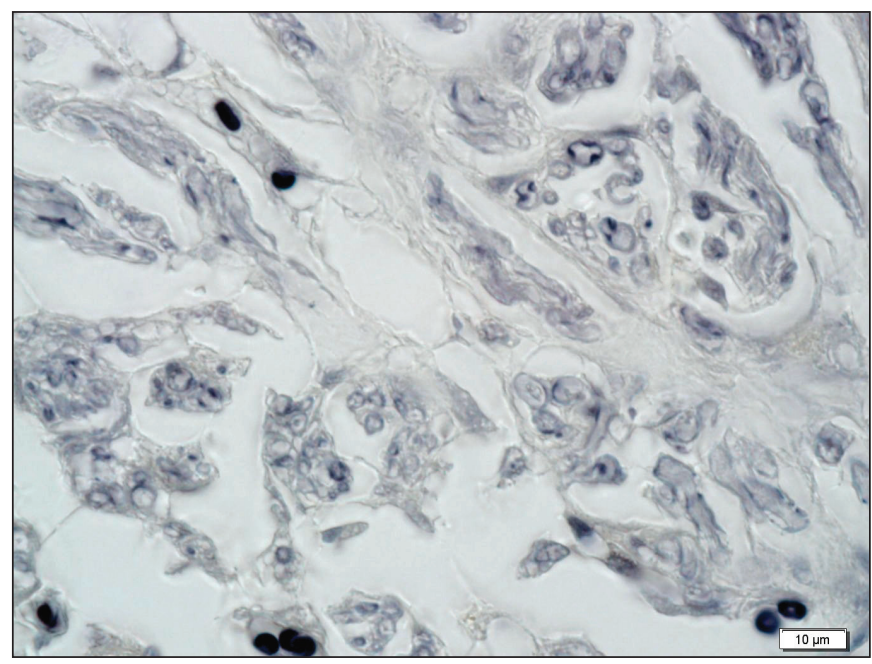

Figure 4: Differentiated nerve bundle showing myelinated neurons (Weil's stain, 400x).

\section{DISCUSSION}

Despite the compromised physiological functions, severely injured peripheral nerves can re-grow to connect their targets (53). For nerve repair, RNA and protein synthesis must be accelerated to soothe the swelling of cell body and reconstitute the original Nissl structure $(22,40)$; then, the survived neurons sprout to produce new dendritic spines. Therefore, formation of new synapses is a timeconsuming mechanism in neuron recovery (1). Angiogenesis, neurogenesis, and synaptic plasticity are three implicated processes in neuro-repair which are naturally activated after different pathological situations in adults. On the other hand, different pharmacological treatments can also stimulate them through endogen neuro-repair phenomena (51). So currently the researchers are focusing on neuro-protective and neurorepair agents, immune system modulation, and enhancing factors of entubulation chambers for nerve repair (5).

Clinical observation of this study revealed that rats showed less lameness and foot-mutilation in groups medicated by simvastatin and L-carnitine. Post injury muscle denervation causes muscle atrophy, which is affected by the timeelapsed and the time forceful effects on functional recovery. L-carnitine can improve nerve regeneration and target organ re-innervation. So, in addition to the less wet muscle weight loss, footpad skin re-innervation occurs in a better way (46). It was also reported that statins improve regeneration of sciatic nerve injured axons and muscle reinnervation $(6,48)$.

Up to $40 \%$ of sensory neurons will be lost after nerve resection, which affects motor function and is clinically significant as an inseparable proprioceptive feedback of normal motor control (45). WRL, as a sensory test, showed no statistical difference between experimented groups. Normal withdrawal time for each paw was reported $4.3 \mathrm{sec}$ or less $(33,50)$. The mean of WRL as the increased required time between two normal paws (left and right) to withdraw was obtained $0.3 \mathrm{sec}$ in the present study. This time was more than $5 \mathrm{sec}$ in the experimental groups here, suggesting that the nerve conduction velocity and consequently mean reflex time of all groups were impaired. Although not significant, the proximity of WRL values of long-term medications (especially SIM1M group) to the control levels can be imputed to longterm administration of oral drugs. Note that long term stress of daily gavage in addition to some controversial reports of deceleration of muscle re-innervation and nerve fiber regeneration by simvastatin long term medication must be considered here (35). However, other studies had proved that simvastatin does not delay regeneration of PNS axons and sciatic nerve compound muscle action potential (cAMP), despite decreasing ubiquinone (mitochondrial respiratory chain enzyme) synthesis (9).

PNS must bend and stretch to correct the limbs' movements in addition to conducting electrical impulses. At early postoperation period, the epineurium forms a layer of fiber membrane followed by collagen which is important in functional recovery of nerve. In this regard, TOA is a reliable neuronal test due to involvement of sensory input, motor response, and cortical integration (20). Analysis of walking and 
TOA in the present experiment indicated that oral treatment of the animals by simvastatin and L-carnitine for one month (SIM1M and LC1M groups) could improve locomotion, where TOAL was considerably close to the normal especially in LC1M group due to close TOA of both paws. Promotion of functional recovery of injured spinal cord in rats by simvastatin had been reported previously; the authors had attributed it to migration of bone marrow stromal cells toward the injured site and up-regulation of endogenous neurotrophins $(16,17)$. For the highest TOA-L of one-month placebo-received group (Plb1M), the authors noted the dominant role of stress due to long-term oral gavage, which is attenuated by benefits of simvastatin and L-carnitine in one-month drug-medicated groups (SIM1M and LC1M).

The presence of adhesions and scar formations adversely affect the functional outcome of peripheral nerve regeneration (49). Macroscopic observation of the adhesion formation during the sciatic nerve exploration revealed that L-carnitinereceived groups (LC1W and $L C 1 M)$ had much less adhesion possibly due to the anti-fibrotic activity of $L$-carnitine. Carnitines have broad-spectrum activities such as antioxidant activity by depleting fatty acid peroxidation and enhancing mitochondrial respiration which reduces free radical production (45).

As a complex pathophysiological process, reconstruction of microenvironments at the injured sites is critical for nerve regeneration and functional recovery. Thus, the early postinjury inflammatory response is crucial to encourage axon growth to its destination. Elevated inflammatory cytokines recruit macrophages to clear the peeled off myelin and axon debris at the site, pave the way for axon growth, and prepare distal stump for receiving the sprouts; so, any delay in debris clearance impedes axon growth $(33,53)$. Although the benefits of inflammation are only restricted to early stage, if prolonged it will be detrimental. The macrophage response will be ceased by down-regulation of pro-inflammatory cytokines and up-regulation of anti-inflammatory ones (33). Therefore, anti-inflammatory, antioxidant, immunomodulatory, and neuroprotective pleiotropic properties of simvastatin $(34,36,38)$ may be helpful in this way. Indeed, simvastatin can reduce infiltration of inflammatory cells via myeloperoxidase inhibition $(48,52)$. L-carnitine facilitates the continuation of normal intercellular interactions between the neuron and glial cells, so it can prevent imbalances in the concentration of local trophic factors to optimize the environment for regeneration (45). In this study, the least inflammation was seen by simvastatin and L-carnitine one-month drug-medicated groups (SIM1M and LC1M), but no difference was observed between simvastatin and L-carnitine.

Vascular network plays an important role in homeostasis, proliferation, and differentiation of somatic stem cells during development and regeneration of tissues (21). The secretion of NGFs by vascular endothelium and somatic stem cells alongside the SCs are critical in peripheral nerve healing (26). SCs, as the main glial cells of PNS, participate in the immune cell penetration by cytokine production in cases of inherited neuropathies, acute inflammatory demyelinating neuropathy, and nerve regeneration (53). Wang et al. reported that greater SCs proliferation in the early stage promotes axon growth, expression of neural skeletal molecules, and nerve regeneration (44). So, adjuvant therapy in this way may result in better outcomes. Here, the greatest neural bundle differentiation was observed in simvastatin one-month group (SIM1M) followed by L-carnitine one-month group (LC1M), but this difference was significant only in SIM1M group compared to the others. This can be due to participation of simvastatin in molecular up-regulation (12), and its probable synergistic effect with SCs by stimulating them to secrete NGFs (15). It is known that lipid and cholesterol metabolism is vital for neuron viability during development and also degenerative diseases $(18,43)$. Thus, simvastatin as well as NGFs enhance neurite outgrowth via increasing lipoprotein uptake by the neuronal cells and affecting membrane formation and dynamics of developing neurons (11).

Neovascularization is also required to supply nutrition to improve the microenvironment for tissue regeneration. In this regard, the endothelial progenitor cells are a cell source for boosting neovascularization (1). In addition to the necessity of blood supply for new neuron survival and development, angiogenesis, as a complicated process of different variables, is directly involved in stimulation of neurogenesis and myelinization $(1,44)$. Although vascular remodeling will increase in areas of newborn neuroblasts, both intact and injured endothelial cells exert various effects on neurogenesis (37). Microvascular endothelial cells secrete NGFs and chemokines which support survival of newly formed neurons and promote re-myelination in damaged axons (44). Increased local generation and up-regulation of angiogenic growth factors (including VEGF, PDGF, TGB- $\beta$ and FGF-2) and some pro-angiogenic factors such as pro-inflammatory cytokines (IL-1 $\beta$, TNF-a) and nitric oxide have an important role in positive clinical outcomes $(1,20,39)$. So, higher microvessel density in injured areas has a positive correlation with longer times of survival. Previous studies reported that sciatic nerve regeneration occurs 1-2 month after surgery in rat models after which the capacity of nerve repair starts to decrease (33). Then, the decline in angiogenesis will occur in the $3^{\text {rd }}$ month, justifying the low $\mathrm{VI}$ in treated animals of this study in comparison with the control group. The least VI was seen in long-term simvastatin and L-carnitine medicated groups (SIM1M and LC1M) which can be attributed to the desired effects of both drugs and long-term treatment.

Migration of neuronal progenitor cells (NPCs) is closely interconnected with blood vessels, indicating that angiogenesis provides oriented guidance to the NPCs, so blood vessels are the main conduits for NPCs chemotaxis toward the injured nervous region (27). SCs functions include myelin-sheath genesis, nerve impulse transmission, and secretion of neurotrophic factors such as BDNF, GDNF, NGF, and NT-3, as well as ECM ingredients that affect positively NPCs and bring an advantageous microenvironment for neuron survival, thus enhancing axonal regeneration (25). In this study, MNF was higher in simvastatin and L-carnitine one-month medicated groups (SIM1M and LC1M) followed by one-week drug-medicated groups (SIM1W and LC1W) compared to the control and placebo-received groups, though this improvement was 
significant only in one-month medications (SIM1M and LC1M groups). Note that the excess myelin prevents axonal growth and limits synapsis (1); so high MNF and low MD of L-carnitine and then simvastatin treated animals especially in long-term medication (LC1M and SIM1M groups) showed a normal structure in histopathology. This implies the involvement of both repaired axon and SCs in myelination and structural recovery of nerve fibers (20). Increased number of nerve fibers in the early months post-nerve repair confirms nerve sprouting. It was reported that L-carnitine treatment results in more fiber presence, increased myelination, and enhanced fiber morphology, suggesting enhanced functional regeneration of axons (46), which was also observed in this study. Despite the reported beneficial effects of simvastatin on preserving morphological parameters of MNF and MD against Wallerian degeneration (7), the non-significant lower values of simvastatin than L-carnitine in MNF and MD can be correlated to possible delay in regeneration of PNS axons and myelin formation by simvastatin. Nevertheless, it had been reported without affecting the electrophysiological conduction (9). Inhibition of remyelination of CNS by prolonged simvastatin treatment had also been reported previously (32), but considering the good nerve remyelination alongside poor functional performance (10), the lower MD values here do not suggest a bad effect alongside the TOAL data.

Angiogenesis is similar and linked to neurogenesis both of which are under the control of intrinsic inherent mechanisms and growth factors; so promoting SCs and NGFs may reduce axon loss (44). L-carnitine stimulation of axon sprouting in preliminary regeneration and restoration of peripheral nerve conduction velocities via normalization of $\mathrm{Na}+, \mathrm{K}+-$-ATPase activity (28), and also angiogenic modulating effects and antioxidant activities of statins in addition to their safety and per oral availability suggest that these agents can potentially earn novel therapeutic indications to reduce neuronal apoptosis (12). The reason is that the combination of sub-therapeutic doses of simvastatin and BMSCs improves neurological outcome, boost angiogenesis and arteriogenesis, and increases the number of engrafted-BMSCs in the ischemic brain (8).

Although the effects of statins on the nervous system had been reported to be controversial in comparison to the benefits of carnitines, the comparison between simvastatin and L-carnitine in the present study revealed no superiority between them. As an immunomodulator drug, simvastatin promotes nerve repair whose benefits are more obvious in long-term medication therapy. Previously, L-carnitine was considered to have regeneration promoter effect on PNS in a short-term treatment following delayed repair, but in this experiment better outcomes were reached by long-term treatment following early repair.

Limitations of this study included impossibility to calculate the sciatic functional index (SFI) due to auto-mutilation; thus, the TOA was used for functional analysis, which has good correlation with SFI and is less affected by auto-mutilation $(33,42)$. Others included no motor testing modalities such as electrophysiology and electromyography to support functional assessments, and lack of axon counting which can bypass the acute inflammatory phase of severe trauma and alleviate the negative effects of un-needed scarring (compression, adhesion, and low vascularity) (50). It is also better to consider the immunohistochemistry assessments which would give valuable data in this field of study (4). Neurogenesis is under the control of intrinsic mechanisms but extrinsic factors (such as physical activity) are important too. The drug therapy was oriented towards stimulating the endogenous neuro-repair processes. Nevertheless, it should be kept in mind that the complete functional recovery of the limb is not proportionate just to neurological recovery; as the neurological function may recover fairly well but overall regaining useful function may be unsatisfactory because of other defects in the limb (40). So, to achieve a successful drug therapy, rehabilitation is the most useful treatment to improve functional recovery (47).

\section{CONCLUSION}

Simvastatin and L-carnitine may accelerate and improve the process of nerve regeneration in a long enough treatment period. As exogenous neurotrophic drugs, the regulatory influence of simvastatin and L-carnitine may be essential to optimize regeneration of damaged nerve fibers which leads to temporary hyper-innervation of the scar. So, these agents can prove themselves as novel therapeutic modalities to decrease neuronal apoptosis.

\section{- ACKNOWLEDGEMENTS}

This work was supported financially by the Vice Chancellor of Research, Shiraz University of Medical Sciences (Grant No. 95-01-56-12727).

The authors would like to thank Dr. Berizi (Department of Food Hygiene and Quality Control, School of Nutrition and Food Sciences, Shiraz University of Medical Sciences, Shiraz, Iran) for his valuable guidance in the statistical analysis of data.

\section{- REFERENCES}

1. Angels Font M, Arboix A, Krupinski J: Angiogenesis, neurogenesis and neuroplasticity in ischemic stroke. Current Cardiology Reviews 6:238-244, 2010

2. Bancroft JD, Gamble M: Theory and practice of histological techniques. $6^{\text {th }}$ ed, China: Churchill Livingstone, Elsevier, 2008

3. Beisse F, Diem R: Immunomodulation and neuroprotection in optic neuritis. Der Ophthalmologe 113:398-401, 2016

4. Bostan H, Cabalar M, Altinay S, Kalkan Y, Tumkaya L, Kanat A, Balik S, Erkut A, Altuner D, Salihoglu Z: Sciatic nerve injury following analgesic drug injection in rats: A histopathological examination. North Clin Istanb 5(3):176-185, 2018

5. Canale ST, Beaty JH, Campbell WC: Peripheral nerve injuries. In: Canale T and Beaty JH ed. Campbell's Operative Orthopaedics. Philadelphia: Mosby, Elsevier Inc., 2013

6. Cloutier FC, Rouleau DM, Hébert-Davies J, Beaumont PH, Beaumont $\mathrm{E}$ : Atorvastatin is beneficial for muscle reinnervation after complete sciatic nerve section in rats. Journal of Plastic Surgery and Hand Surgery 47:446-450, 2013 
7. Corso CR, Martins DF, Borges SC, Beltrame OC, Telles JEQ, Buttow NC, Werner MFP: Effect of simvastatin on sensorial, motor, and morphological parameters in sciatic nerve crush induced-neuropathic pain in rats. Inflammopharmacology 26:793-804, 2018

8. Cui X, Chopp M, Zacharek A, Roberts C, Lu M, SavantBhonsale S, Chen J: Chemokine, vascular and therapeutic effects of combination Simvastatin and BMSC treatment of stroke. Neurobiology of Disease 36:35-41, 2009

9. Daglioglu E, Berker M, Demirci M, Tuncel M, Karabulut E, Tuncel A: Microscopic and electrophysiological changes on regenerating sciatic nerves of rats treated with simvastatin. Folia Neuropathologica 48:49-56, 2010

10. de Medinaceli L: Interpreting nerve morphometry data after experimental traumatic lesions. Journal of Neuroscience Methods 58:29-37, 1995

11. Do HT, Bruelle C, Pham DD, Jauhiainen M, Eriksson $O$, Korhonen LT, Lindholm D: Nerve growth factor (NGF) and pro-NGF increase low-density lipoprotein (LDL) receptors in neuronal cells partly by different mechanisms: Role of LDL in neurite outgrowth. Journal of Neurochemistry 136:306-315, 2016

12. Elewa HF, El-Remessy AB, Somanath PR, Fagan SC: Diverse effects of statins on angiogenesis: New therapeutic avenues. Pharmacotherapy: The Journal of Human Pharmacology and Drug Therapy 30:169-176, 2010

13. Ghavami SM, Farjah GH, Shoorei H, Dolatkhah MA: Functional recovery of transected peripheral nerve by means of microwave irradiated collagen nerve guides filled with chick embryonic cerebrospinal fluid in rats. Crescent Journal of Medical and Biological Sciences 4:194-199, 2017

14. Grinsell D, Keating CP: Peripheral nerve reconstruction after injury: A review of clinical and experimental therapies. BioMed Research International 2014:1-13,2014

15. Guo Q, Liu C, Hai B, Ma T, Zhang W, Tan J, Fu X, Wang H, Xu $Y$, Song C: Chitosan conduits filled with simvastatin/Pluronic F-127 hydrogel promote peripheral nerve regeneration in rats. J Biomed Mater Res B Appl Biomater 106(2):787-799, 2018

16. Han X, Yang N, Cui Y, Xu Y, Dang G, Song C: Simvastatin mobilizes bone marrow stromal cells migrating to injured areas and promotes functional recovery after spinal cord injury in the rat. Neuroscience Letters 521:136-141, 2012

17. Han X, Yang N, Xu Y, Zhu J, Chen Z, Liu Z, Dang G, Song C: Simvastatin treatment improves functional recovery after experimental spinal cord injury by upregulating the expression of BDNF and GDNF. Neuroscience Letters 487:255-259, 2011

18. Hartmann T, Kuchenbecker J, Grimm MO: Alzheimer's disease: The lipid connection. Journal of Neurochemistry 103:159-170, 2007

19. Helvacioglu F, Kandemir E, Karabacak B, Karatas I, Pecen A, Ercan I, Sencelikel T, Dagdeviren A: Effect of creatine on rat sciatic nerve injury: A comparative ultrastructural study. Turk Neurosurg 28(1):128-136, 2018

20. Ilkhanizadeh B, Zarei L, Farhad N, Bahrami-Bukani M, Mohammadi R: Mast cells improve functional recovery of transected peripheral nerve: A novel preliminary study. Injury 48:1480-1485, 2017
21. Kamei N, Atesok K, Ochi M: The use of endothelial progenitor cells for the regeneration of musculoskeletal and neural tissues. Stem Cells International 2017:7, 2017

22. Kandel ER, Schwartz JH, Jessell TM, Siegelbaum SA, Hudspeth AJ, Mack S: Principles of Neural Science, $5^{\text {th }}$ ed. USA: McGraw-Hill Companies, 2013

23. Karanth S, Yang G, Yeh J, Richardson P: Nature of signals that initiate the immune response during Wallerian degeneration of peripheral nerves. Exp Neurol 202:161-166, 2006

24. Kilkenny C, Browne W, Cuthill IC, Emerson M, Altman DG, Group NCRRGW: Animal research: Reporting in vivo experiments: The ARRIVE guidelines. British Journal of Pharmacology 160:1577-1579, 2010

25. Kim HS, Lee J, Lee DY, Kim YD, Kim JY, Lim HJ, Lim S, Cho YS: Schwann cell precursors from human pluripotent stem cells as a potential therapeutic target for myelin repair. Stem Cell Reports 8:1714-1726, 2017

26. Kizilay Z, Aktas S, Kahraman Cetin N, Bakay Ilhan D, Ersoy G, Erken HA: Effect of systemic application of bone marrowderived mesenchymal stem cells on healing of peripheral nerve injury in an experimental sciatic nerve injury model. Turk Neurosurg 2017 (Epub ahead of print)

27. Kojima T, Hirota Y, Ema M, Takahashi S, Miyoshi I, Okano H, Sawamoto K: Subventricular zone-derived neural progenitor cells migrate along a blood vessel scaffold toward the poststroke striatum. Stem Cells 28:545-554, 2010

28. Kostopoulos VK, Davis CL, Terzis JK: Effects of acetylo-Lcarnitine in end-to-side neurorrhaphy: A pilot study. Microsurgery 29:456-463, 2009

29. Lee H, Jo EK, Choi SY, Oh SB, Park K, Kim JS, Lee SJ: Necrotic neuronal cells induce inflammatory Schwann cell activation via TLR2 and TLR3: Implication in Wallerian degeneration. Biochem. Biophys Res Commun 350:742-747, 2006

30. Lu VM, Goyal A, Quinones-Hinojosa A, Chaichana KL: Updated incidence of neurological deficits following insular glioma resection: A systematic review and meta-analysis. Clinical Neurology and Neurosurgery 177:20-26, 2019

31. Masters DB, Berde CB, Dutta SK, Griggs CT, Hu D, Kupsky $\mathrm{W}$, Langer R: Prolonged regional nerve blockade by controlled release of local anesthetic from a biodegradable polymer matrix. Anesthesiology 79:340-346, 1993

32. Miron VE, Zehntner SP, Kuhlmann T, Ludwin SK, Owens T, Kennedy TE, Bedell BJ, Antel JP: Statin therapy inhibits remyelination in the central nervous system. The American Journal of Pathology 174:1880-1890, 2009

33. Moattari M, Kouchesfehani HM, Kaka G, Sadraie SH, Naghdi M: Study of transected sciatic nerve repair by biodegradable membrane and betamethasone in adult albino wistar rats. Turk Neurosurg 2017 (Epub ahead of print)

34. Morishita S, Oku H, Horie T, Tonari M, Kida T, Okubo A, Sugiyama T, Takai S, Hara H, Ikeda T: systemic simvastatin rescues retinal ganglion cells from optic nerve injury possibly through suppression of astroglial NF-kB activation. PLOS ONE 9:e84387, 2014

35. Otruba P, Kanovsky P, Hlustik P: Treatment with statins and peripheral neuropathy: Results of 36 -months a prospective clinical and neurophysiological follow-up. Neuroendocrinol Lett 32:688-690, 2011 
36. Pan HC, Yang DY, Ou YC, Ho SP, Cheng FC, Chen CJ: Neuroprotective effect of atorvastatin in an experimental model of nerve crush injury. Neurosurgery 67:376-389, 2010

37. Plane JM, Andjelkovic AV, Keep RF, Parent JM: Intact and injured endothelial cells differentially modulate postnatal murine forebrain neural stem cells. Neurobiology of Disease $37: 218-227,2010$

38. Shi XQ, Lim TKY, Lee S, Zhao YQ, Zhang J: Statins alleviate experimental nerve injury-induced neuropathic pain. Pain 152:1033-1043, 2011

39. Shimotake J, Derugin N, Wendland M, Vexler ZS, Ferriero DM: Vascular endothelial growth factor receptor-2 inhibition promotes cell death and limits endothelial cell proliferation in a neonatal rodent model of stroke. Stroke 41:343-349, 2010

40. Snell RS: Clinical Neuroanatomy. Philadelphia: Lippincott Williams \& Wilkins, 2010

41. Tong F, Dong B, Chai R, Tong K, Wang Y, Chen S, Zhou X, Liu $D$ : Simvastatin nanoparticles attenuated intestinal ischemia/ reperfusion injury by downregulating BMP4/COX-2 pathway in rats. Int J Nanomedicine 12:2477-2488, 2017

42. Varejao AS, Cabrita AM, Geuna S, Melo-Pinto P, Filipe VM, Gramsbergen A, Meek MF: Toe out angle: A functional index for the evaluation of sciatic nerve recovery in the rat model. Experimental Neurology 183:695-699, 2003

43. Verghese PB, Castellano JM, Holtzman DM: Apolipoprotein E in Alzheimer's disease and other neurological disorders. The Lancet Neurology 10:241-252, 2011

44. Wang J, Ding F, Gu Y, Liu J, Gu X: Bone marrow mesenchymal stem cells promote cell proliferation and neurotrophic function of Schwann cells in vitro and in vivo. Brain Research 1262:715, 2009

45. Wilson AD, Hart A, Brannstrom T, Wiberg M, Terenghi G: Primary sensory neuronal rescue with systemic acetyl-Lcarnitine following peripheral axotomy. A dose-response analysis. British Journal of Plastic Surgery 56:732-739, 2003
46. Wilson AD, Hart A, Wiberg M, Terenghi G: Acetyl-I-carnitine increases nerve regeneration and target organ reinnervation-a morphological study. Journal of Plastic, Reconstructive \& Aesthetic Surgery 63:1186-1195, 2010

47. Wolf SL, Winstein CJ, Miller JP, Taub E, Uswatte G, Morris D, Giuliani C, Light KE, Nichols-Larsen D, Investigators E: Effect of constraint-induced movement therapy on upper extremity function 3 to 9 months after stroke: The EXCITE randomized clinical trial. Jama 296:2095-2104, 2006

48. Xavier AM, Serafim KG, Higashi DT, Vanat N, Flaiban KK, Siqueira CP, Venâncio EJ, Ramos Sde P: Simvastatin improves morphological and functional recovery of sciatic nerve injury in Wistar rats. Injury 43:284-289, 2012

49. Yapici AK, Bayram Y, Akgun H, Gumus R, Zor F: The effect of in vivo created vascularized neurotube on peripheric nerve regeneration. Injury 48(7):1486-1491, 2017

50. Zadegan SA, Firouzi M, Nabian MH, Zanjani LO, Ashtiani AM, Kamrani RS: Two-stage nerve graft in severe scar: A time-course study in a rat model. Archives of Bone and Joint Surgery $3: 82,2015$

51. Zhang ZG, Chopp M: Neurorestorative therapies for stroke: Underlying mechanisms and translation to the clinic. Lancet Neurology 8:491-500, 2009

52. Zhao Y, Feng Q, Huang Z, Li W, Chen B, Jiang L, Wu B, Ding W, Xu G, Pan H: Simvastatin inhibits inflammation in ischemiareperfusion injury. Inflammation 37:1865-1875, 2014

53. Zhao Y, Wang Y, Gong J, Yang L, Niu C, Ni X, Wang Y, Peng S, Gu X, Sun C, Yang Y: Chitosan degradation products facilitate peripheral nerve regeneration by improving macrophageconstructed microenvironments. Biomaterials 134:64-77, 2017 